\title{
Factors involved in treatment preference in patients with renal cancer: pazopanib versus sunitinib
}

\author{
Catherine C Mitchell \\ Omi A Parikh \\ Lancashire Teaching Hospitals \\ NHS Foundation Trust, Preston, \\ Lancashire, UK
}

\author{
This article was published in the following Dove Press journal: \\ Patient Preference and Adherence \\ 22 April 2014 \\ Number of times this article has been viewed
}

\begin{abstract}
The last decade has seen a surge in the treatment options for metastatic renal cell carcinoma and life expectancies are now approaching 3 years from diagnosis. There is some suggestion that, for now at least, we may have reached a plateau in efficacy. Patients are often stable and on treatment for years rather than months. Attention has therefore shifted to a focus on patient preference rather than reported frequency of toxicities. The standard first-line treatment for metastatic clear-cell renal cancer is either sunitinib or pazopanib. The COMPARZ trial has shown that sunitinib and pazopanib have similar efficacy. The PISCES trial, with its unique design, has evaluated patient preference between pazopanib and sunitinib. This review explores the factors involved in treatment preference in patients with renal cancer and in particular the choice between pazopanib and sunitinib.
\end{abstract}

Keywords: PISCES, patient preference, sunitinib, pazopanib

\section{Introduction}

Renal cell carcinoma (RCC) accounts for $90 \%$ of kidney cancers, and comprises around $3 \%$ of all new adult cases. Kidney cancer is the eighth most common cancer in the UK for men and 14th most common for women. There are two peaks in incidence, the first in childhood at age 1-4 years and then the majority being in people aged over 60 years. Age-standardized rates per 100,000 newly diagnosed cases of cancer in 2011 were 14.0 for men and 7.5 for women. Between 2008 and 2010, the direct age-standardized mortality rate per 100,000 of population deaths from kidney cancer was 5.6 for men and 2.8 for women. ${ }^{1}$

For tumors that are confined to the kidney, surgical resection forms the basis of treatment; however, recurrence develops in approximately $40 \%$ of patients treated for a localized tumor. ${ }^{2}$ Approximately one third of patients present with distant metastases, ${ }^{3}$ and the majority of these cannot be cured, with a negative correlation between advancing age at diagnosis and survival rates. For patients who are under the age of 50 years at diagnosis, the survival rate is twice that of patients aged over 80 years.

\section{Background}

Prior to 2005, there were few treatment options for patients with metastatic RCC and the prognosis for advanced disease was poor, with 5-year survival rates around $10 \%$. Very fit patients could be treated with interferon-alpha or high-dose interleukin-2, for which some long-term responses are seen. ${ }^{4}$ Only around $5 \%$ of patients are eligible for this treatment, and the high doses come with significant toxicity and are unlikely
Correspondence: Omi A Parikh Royal Preston Hospital, Sharoe Green Lane North, Fulwood, Preston, Lancashire, PR2 9HT, UK Tel +44I7 72522089

Email omi.parikh@Ithtr.nhs.uk 
to benefit the "average" patient with extensive tumor burden and adverse prognostic factors.

Cytotoxic chemotherapy, used singly or in combination, has had poor response rates in the region of 5\%. ${ }^{5} \mathrm{RCC}$ was therefore deemed to be chemotherapeutically resistant and so, not surprisingly, when the "magic bullet" era of small molecule targeted treatments came along, there was much publicity in the media. ${ }^{6}$

The study of hereditary syndromes such as von Hippel-Lindau (VHL) disease and tuberous sclerosis have aided the understanding and identification of pathways involved in the development of RCC and subsequently the potential targets for treatment.

The majority (up to $80 \%$ of sporadic cases) of clear-cell carcinoma involves inactivation of the $V H L$ gene. The $V H L$ gene acts as a tumor suppressor gene encoding for regulation of vascular endothelial growth factor (VEGF) and plateletderived growth factor (PDGF) via hypoxia-inducible factors (HIF-1 $\alpha$ and HIF-2 $\beta$ ). With the $V H L$ gene inactivated, VEGF receptors and PDGF receptors are overexpressed, resulting in promotion of tumor angiogenesis, growth, and metastasis. ${ }^{7}$ HIF- $1 \alpha$ activity is also regulated by other growth factors, including the mammalian target of rapamycin (mTOR) and Raf protein kinase signaling pathways. VEGR, mTOR, and PDGF are therefore obvious targets for treatment.

Table 1 summarizes the licensed treatment options for metastatic RCC. Sorafenib was first approved in 2005, and followed closely by sunitinib, which is a multitargeted receptor inhibitor of tyrosine kinases including the VEGF receptor and PDGF receptor. ${ }^{8}$ Sunitinib was first introduced in 2006, having been shown to be superior to interferonalpha by improving median progression-free survival from 5 to 11 months $(P=0.001)$ and improving overall survival from 21.8 to 26.4 months $(P=0.051) .{ }^{9}$ Temsirolimus was approved in 2007, having been shown to improve overall survival in patients with poor prognostic metastatic RCC from 7.3 months with interferon to 10.9 months with temsirolimus $(P \leq 0.001) .{ }^{10}$ Bevacizumab was first approved by the Food and Drug Administration (FDA) in 2009, after Escudier et al showed in AVOREN (the Phase III Trial of Bevacizumab Plus Interferon Alfa-2a in Patients With Metastatic Renal Cell Carcinoma) in 2007 that addition of bevacizumab to interferon-alpha improved progressionfree survival from 5.4 to 10.2 months $(P=0.0001)$, but no overall survival was seen (23.3 months compared with 21.3, $P=0.336) .{ }^{11}$ Everolimus was also approved in 2009 for the treatment of second-line RCC, having shown an improvement in progression-free survival to 4 months compared with 1.9 months on placebo. ${ }^{12}$ Pazopanib was approved in 2010. More recently, axitinib, a novel tyrosine kinase inhibitor acting on the VEGF receptor at a subnanomolar level, ${ }^{13}$ was approved for second-line treatment by the FDA in January 2012. This was on the basis of the AXIS (Comparative effectiveness of axitinib versus sorafenib in advanced renal cell carcinoma) trial which enrolled 723 patients with metastatic clear-cell RCC to receive axitinib or sorafenib. ${ }^{14}$ Only one prior therapy could have been given, but this could have been cytokines, high-dose interleukin-2 or VEGF. The trial demonstrated a clinical advantage for axitinib, improving progression-free survival from 4.7 months with sorafenib to 6.7 months with axitinib $(P<0.0001)$. This trial is particularly interesting because it suggests that the disease retains a response to VEGF inhibitors throughout, even when given in sequence, at least through the first two lines of treatment.

Axitinib has also been trialed in the first-line setting; AGILE was a Phase III trial enrolling 288 patients with

Table I Drugs approved for use in metastatic renal cell carcinoma

\begin{tabular}{|c|c|c|c|c|c|c|}
\hline Agent & FDA approval & NICE approval & Indication & Comparator & PFS (months) & OS (months) \\
\hline Interleukin- $2^{4}$ & 1992 & Predates NICE & $\begin{array}{l}\text { First-line } \\
\text { ECOG 0-I }\end{array}$ & None & \multicolumn{2}{|c|}{$\begin{array}{l}19 \text { (median duration response for } \\
\text { partial responders) }\end{array}$} \\
\hline IFN $\alpha^{32}$ & 2001 & Predates NICE & $\begin{array}{l}\text { First-line } \\
\text { ECOG 0-I }\end{array}$ & None & 5 & $1 \mathrm{I} .4$ \\
\hline Sorafenib ${ }^{33}$ & 2005 & Not approved & First-line & Placebo & 5.5 & 19.3 \\
\hline Sunitinib 9 & 2006 & 2009 & First-line & $\mathrm{IFN} \alpha$ & 11 & 26.4 \\
\hline Temsirolimus $^{10}$ & 2007 & Available via CDF & $\begin{array}{l}\text { First-line } \\
\text { Poor risk }\end{array}$ & IFN $\alpha$ & 5.5 & 10.9 \\
\hline Bevacizumab/IFN"I & 2009 & Not approved & First-line & IFN $\alpha$ & 10.2 & 23.3 \\
\hline Everolimus $^{12}$ & 2009 & Available via CDF & Second-line & Placebo & 4.0 & 14.8 \\
\hline Pazopanib ${ }^{21}$ & 2010 & 2011 & First-line & Placebo & 11.1 & 22.9 \\
\hline Axitinib $^{14,34}$ & 2012 & Available via CDF & Second-line & Sorafenib & 6.7 & 20.1 \\
\hline
\end{tabular}

Abbreviations: FDA, Food and Drug Administration; PFS, progression-free survival; OS, overall survival; CDF, Cancer Drugs Fund, UK; NICE, National Institute for Clinical Excellence; ECOG, Eastern Cooperative Oncology Group; IFN $\alpha$, interferon-alpha. 
metastatic clear-cell RCC who had received no prior treatment to receive axitinib or sorafenib. ${ }^{15}$ The groups were fairly well balanced, but 5\% more in the sorafenib arm had had nephrectomy and had a better performance status. The trial failed to reach the primary end point despite clearly showing axitinib to be an active drug, given that progressionfree survival improved with axitinib from 9.8 months to 5.5 months. This lack of statistical significance is suggested to have been a direct result of the trial design rather than the efficacy of axitinib.

Hence, from essentially no significant effective drugs against renal cancer, there are now seven different licensed drugs in just 8 years. Five of the seven drugs are oral tablets that are taken by the patient at home until disease progression, and to some extent similar to management of chronic conditions. Five of the drugs target the HIF/VEGF axis (sorafenib, sunitinib, bevacizumab, pazopanib, axitinib) and two target the mTOR pathway (everolimus, temsirolimus).

In each group, the agents have similar mechanisms of action but different in vitro kinase inhibitory profiles, and therefore different associated side effects. Until the recent publication of the AXIS and COMPARZ (Pazopanib Versus Sunitinib in the Treatment of Locally Advanced and/or Metastatic Renal Cell Carcinoma) trials, there have been few head-to-head studies between these seven new drugs, so choice based upon efficacy was difficult. COMPARZ was a noninferiority trial looking at patients with locally advanced or metastatic clear-cell RCC who had received no prior systemic therapy. ${ }^{16}$ In total, 927 patients were randomized to receive pazopanib $800 \mathrm{mg}$ once daily continuously or sunitinib $50 \mathrm{mg}$ once daily 4 weeks on and 2 weeks off. Overall, the median progression-free survival with pazopanib was 8.4 months compared with 9.5 months for sunitinib, with a non-inferior hazard ratio of 1.04. Additionally, the median overall survival was 28.4 months for pazopanib compared with 29.3 months for sunitinib with a hazard ratio of 0.91 . These findings suggest that both agents provide similar high-quality care.

In the setting where patients are on the treatment for many months or years, patient preference becomes all the more relevant. Further agents are continuously in development, but for now at least, there has been a shift from efficacy to optimal therapy regimens/combinations, management of side effects, and patient preference. As survival rates approach 3 years from diagnosis, quality of life, particularly whilst on treatment, becomes all the more important. After all, there is no point in having a medication that affects patients so much that they decline to take it because of side effects and worsened quality of life.

\section{Importance of patient preference studies}

Ten years ago, metastatic RCC would have been viewed as a rapidly fatal disease. With the recent improvement in overall survival rates, it can now be viewed as a chronic disease. ${ }^{17}$ Patients started on first-line treatment for metastatic RCC are likely to be on treatment for a substantial part of their remaining life post diagnosis. On average, for patients in a favorable risk group, median time to progression on first-line VEGF-targeted therapy is 16.6 months (15 months for intermediate-risk patients). ${ }^{18}$ The tolerability of treatment is therefore of upmost importance and if there is an equal choice between treatments, then patient preference studies aid the decision-making.

Similar issues were raised in breast cancer, with more and more patients taking aromatase inhibitors for longer. Tolerability became a significant patient concern and a regular discussion topic in clinics. It has long been known in breast cancer that those who are given a share in the decisionmaking and are better informed report greater autonomy, reduced psychologic morbidity, and improved satisfaction. A similar crossover trial design to that used in the PISCES (Patient Preference Study of Pazopanib Versus Sunitinib in Advanced or Metastatic Kidney Cancer) trial aimed to evaluate the impact of giving patients a choice. ${ }^{19}$ Patients were randomized in a single-blind crossover trial (only the physicians were blinded to treatment due to cost of repackaging) to receive anastrozole or letrozole daily for 4 weeks, one week off then crossover for 4 weeks. A formal quality of life assessment was done. Patients in this trial actually wanted the opportunity to test both drugs and warmly welcomed extra involvement in the decision-making process via a crossover maneuver if side effects developed. This choice may lead to greater quality of life scores.

A conclusion from the trial were that patients preferred letrozole, but toxicity and quality of life strongly correlate with patient preference, and giving patients a choice improved their quality of life. The trial also concluded that patient preference is now a legitimate and useful end point for future crossover studies. Despite this, there have been remarkably few oncology studies over the last ten years in the metastatic setting that used the same patient to test different drugs and express a preference.

\section{PISCES trial}

PISCES is one of two studies comparing pazopanib with sunitinib. The other study (COMPARZ) also indicated that safety, quality of life, and patient preference may be important 
factors to consider when several effective treatment options are available. The unique crossover design of the PISCES study enabled investigation of whether tolerability and safety differences between pazopanib and sunitinib are meaningful to the patient. Efficacy, although assessed, was not used to influence patient preference because this study was intended to supplement the main efficacy study (COMPARZ).

Pazopanib is administered orally at a recommended dose of $800 \mathrm{mg}$ once daily. The dose can be reduced as required in order to manage toxicity and adjusted in steps of $200 \mathrm{mg}$. Pazopanib was first recommended by the National Institute for Clinical Excellence in February 2011 as a first-line treatment option for people with advanced RCC who have not received prior cytokine therapy and have an Eastern Cooperative Oncology Group (ECOG) performance status of 0 or $1 .^{20}$ This recommendation followed Phase III data showing an improvement in progression-free survival from 2.8 months to 11.1 months on pazopanib compared with placebo for treatment-naïve patients. ${ }^{21}$ Response rates of $32 \%$ on pazopanib versus $4 \%$ on placebo were seen.

The PISCES trial had a unique crossover design allowing each patient to experience both drugs and then choose which they prefer. ${ }^{22}$ This trial is the first of its kind in advanced RCC to have patient preference as the primary endpoint. The inclusion criteria stipulated that patients had to be treatment-naïve for metastatic RCC, with disease being locally advanced or metastatic, and of any histology. Patients had to have an ECOG performance status of 0 or 1 , adequate cardiac and renal function, and measurable and non-measurable disease. Excluded were patients with a poor Memorial Sloan-Kettering Cancer Center risk grouping, and those with a history of other malignancies or central nervous system metastasis. Patients were randomized in a 1 to 1 double-blind setting. One hundred and sixty-nine patients were enrolled to receive either pazopanib $800 \mathrm{mg}$ daily for 10 weeks first (period 1) followed by sunitinib $50 \mathrm{mg}$ for 4 weeks on a 2 weeks off and 4 weeks on basis (period 2) or vice versa (see Figure 1). There was a 2-week washout period during which they received placebo and tablets were over encapsulated to provide visually identical tablets. Patients and physician preference was then recorded prior to unblinding and prior to disclosure of final tumor assessment by patients who had received at least one dose of both treatments. Patients were asked to select which drug they preferred or if they had no preference. They were also asked which factors influenced this preference and the most important reason for their preference. The trial stratified for ECOG performance status and number of metastatic sites ( 0 and 1 versus $2+$ ).

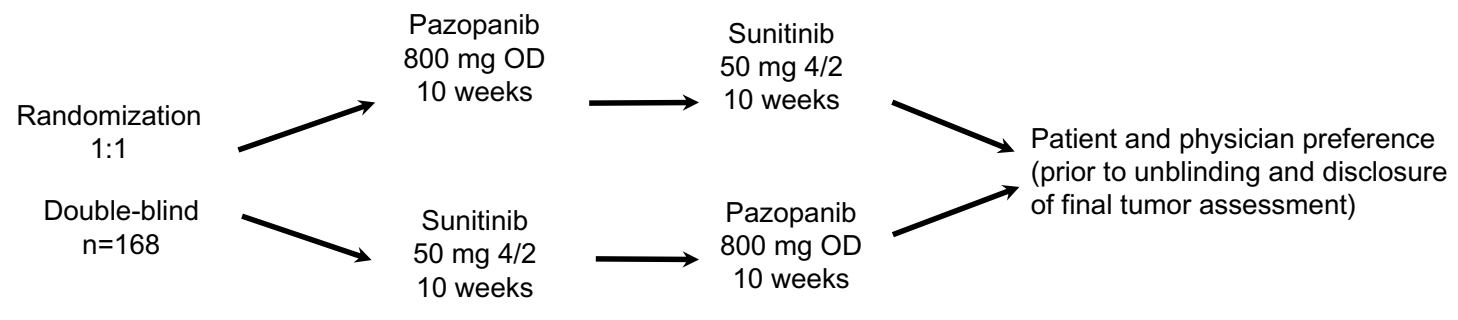

Two-week washout

\begin{tabular}{|l|l|l|l|l|l|l|l|l|l|l|l|}
\hline \multicolumn{1}{|c|}{ Week } & $\mathbf{0}$ & $\mathbf{4}$ & $\mathbf{6}$ & $\mathbf{8}$ & $\mathbf{1 0}$ & $\mathbf{1 2}$ & $\mathbf{1 4}$ & $\mathbf{1 6}$ & $\mathbf{1 8}$ & $\mathbf{2 0}$ & $\mathbf{2 2}$ \\
\hline CT assessment & $\checkmark$ & & & & & $\checkmark$ & & & & & $\checkmark$ \\
\hline $\begin{array}{l}\text { Patient } \\
\text { preference }\end{array}$ & & & & & & & & & & & $\checkmark$ \\
\hline FACIT-Fatigue & $\checkmark$ & $\checkmark$ & $\checkmark$ & $\checkmark$ & $\checkmark$ & $\checkmark$ & $\checkmark$ & $\checkmark$ & $\checkmark$ & $\checkmark$ & $\checkmark$ \\
\hline SQLQ & $\checkmark$ & $\checkmark$ & $\checkmark$ & $\checkmark$ & $\checkmark$ & $\checkmark$ & $\checkmark$ & $\checkmark$ & $\checkmark$ & $\checkmark$ & $\checkmark$ \\
\hline
\end{tabular}

Figure I PISCES study design.

Note: Reprinted with permission. ( 2012 American Society of Clinical Oncology. All rights reserved. Escudier BJ, Porta C, Bono P. Patient preference between pazopanib and sunitinib: results of a randomized double-blind, placebo-controlled, cross-over study in patients with metastatic renal cell carcinoma - PISCES study, NCT 010643 I0. J Clin Oncol. 2012;30(Suppl 18):Abstr CRA4502.22

Abbreviations: CT, computed tomography; OD, once daily; SQLQ, Supplementary Quality of Life Questionnaire; FACIT-Fatigue, Functional Assessment of Chronic Illness Therapy for fatigue score. 
Secondary endpoints included health-related quality of life, taking into account general health, fatigue, mouth, throat, and hand-foot syndrome. Dose modifications were monitored, as well as safety and physician preference. The statistical design was done assuming that there would be a greater than $20 \%$ difference in preference between pazopanib and sunitinib, with $50 \%$ of patients preferring one drug, $30 \%$ preferring the other, and $20 \%$ having no preference.

Health-related quality of life was assessed twice weekly using the Functional Assessment of Chronic Illness Therapy for fatigue score (FACIT-fatigue), a 13-item FACIT scale questionnaire. Supplementary Quality of Life Questionnaire was also assessed twice weekly. This instrument measures severity and impact of fatigue on functioning and health-related quality of life experienced in the past 7 days. Radiologic assessment with computed tomography was done at baseline, during the washout period, and at the end of the study.

From the results presented at the 2012 annual scientific meeting of the American Society of Clinical Oncology, we can see that patients were quite evenly matched in terms of key baseline characteristics. As expected, clear-cell histology was the most common pathology, with slightly more cases $(93 \%)$ in the sunitinib first group versus the pazopanib first group (87\%). It is interesting to note that there was a large range in time from diagnosis to trial entry in both groups of patients. The overall median range was 7.7 months, with a maximum of 241 months.

There were withdrawals during the course of the study due to patients not reaching the second round of treatment (due either to progression or adverse events) as well as progressive disease or adverse events after both rounds of treatment. This left 54 patients in the pazopanib first group and 60 patients in the sunitinib first group as the primary analysis population.

At this point, the question asked was "now that you have completed both treatments, which of the two drugs would you prefer to continue to take as the treatment for your cancer, assuming that both drugs will work equally well in treating your cancer?". Choice of answers was "first treatment", "second treatment", or "no preference". There was a significant patient preference in favor of pazopanib (70\% versus $22 \%, P<0.001$ ). When it came to looking at patient preference according to treatment order, there was still a large difference. Eighty percent of those who were given pazopanib then sunitinib preferred pazopanib, compared with $62 \%$ of those who were given sunitinib first. The most common reason for preferring pazopanib was "quality of life in general was better" (see Table 2). This was followed by
Table 2 Factors to consider in treatment preference between pazopanib and sunitinib

\begin{tabular}{|c|c|c|}
\hline \multicolumn{2}{|c|}{ Patient factors (reduced impact on life) } & \multirow[t]{2}{*}{ Physician factors } \\
\hline $\begin{array}{l}\text { Patient preference } \\
\text { for pazopanib }\end{array}$ & $\begin{array}{l}\text { Patient preference } \\
\text { for sunitinib }\end{array}$ & \\
\hline $\begin{array}{l}\text { Improved quality } \\
\text { of life }\end{array}$ & Diarrhea & Efficacy \\
\hline Fatigue & $\begin{array}{l}\text { Improved quality } \\
\text { of life }\end{array}$ & Concordance \\
\hline Changes in food taste & Fatigue & Patient tolerance \\
\hline Nausea/vomiting & Nausea/vomiting & Patient preference \\
\hline $\begin{array}{l}\text { Soreness in } \\
\text { mouth/throat }\end{array}$ & Appetite & $\begin{array}{l}\text { Mode of } \\
\text { administration }\end{array}$ \\
\hline $\begin{array}{l}\text { Soreness in } \\
\text { hands/feet }\end{array}$ & Stomach pain & $\begin{array}{l}\text { Ability to adjust } \\
\text { dose/regimen }\end{array}$ \\
\hline Stomach pain & $\begin{array}{l}\text { Soreness in mouth/ } \\
\text { throat }\end{array}$ & Comorbidities \\
\hline Diarrhea & $\begin{array}{l}\text { Soreness in } \\
\text { hands/feet }\end{array}$ & $\begin{array}{l}\text { Experience with } \\
\text { the drug }\end{array}$ \\
\hline Hair color change & Changes in food taste & Support structure \\
\hline Time on treatment & Hair color change & \\
\hline
\end{tabular}

Note: Data from Escudier BJ et al. ${ }^{22}$

less fatigue, reduced food taste changes, less impact from nausea/vomiting, mouth soreness, hand-foot syndrome, loss of appetite, stomach pain, diarrhea, and change in hair color. Of the patients who preferred sunitinib, the commonest reason given was "diarrhea had less impact on my life". These answers were again reflected when patients chose the most important reason for preference. Patients were asked "If you had to choose one reason, which of the above symptoms is the most important reason for your preference?". Fatigue was cited as most important in patients who preferred pazopanib and diarrhea in patients who preferred sunitinib. Physician preference again favored pazopanib, with an overall preference of $69 \%$ and good concordance between patient and physician preference.

Response per Response Evaluation Criteria In Solid Tumors (RECIST) criteria was assessed by the investigators and therefore not confirmed, but there was no statistically significant difference in radiologic response rate, with complete response rates of $1 \%$ in both study arms, and partial responses in $18 \%$ of the pazopanib first and $20 \%$ of the sunitinib first patients. Stable disease included partial response and nonprogressive disease for patients with non-measurable disease, and was seen in $42 \%$ of patients who received pazopanib first and $53 \%$ of those who received sunitinib first. Progressive disease was seen in $20 \%$ of pazopanib first patients and $15 \%$ of sunitinib first patients.

The FACIT-fatigue tool reflected patient self-reporting of less perceived fatigue on pazopanib but this did not 
meet the minimally important difference threshold. The Supplementary Quality of Life Questionnaire confirmed that patients experienced less hand-foot syndrome with pazopanib.

Dose modifications were made for $20 \%$ of patients on sunitinib and for $13 \%$ of patients on pazopanib. Diarrhea was the most common adverse event for all patients (42\% whilst on pazopanib and $32 \%$ whilst on sunitinib, but was grade $3 / 4$ in $<1 \%$ ). Hypertension was the most common grade $3 / 4$ toxicity whilst on sunitinib $(9 \%)$ and on pazopanib $(8 \%)$. This was followed by grade $3 / 4$ events of asthenia, hand-foot syndrome, and fatigue. Fewer patients (1\%) had neutropenia on pazopanib compared with $7 \%$ on sunitinib, but more patients on pazopanib (7\%) had a significant rise in alanine transaminase than those on sunitinib (3\%).

The frequency and severity of observed rates of myelosuppression varies between the multikinase angiogenesis inhibitors. This variation is thought to be due to "off-target" activity and varying selectivity. ${ }^{23}$ Sunitinib and pazopanib both inhibit the VEGF and PDGF receptors, but sunitinib inhibits further kinases, including Flt-3, which appears to be essential for optimal production of lymphoid progenitor cells from stem cells and is a potential explanation for the difference in observed rates of myelosuppression.

In summary, significantly more patients preferred pazopanib over sunitinib, with the most important reason being less fatigue as reflected in the FACIT-fatigue tool. There was a high level of concordance between patient and physician preference and a greater incidence of diarrhea with pazopanib and hematologic toxicity with sunitinib.

\section{Analysis of PISCES Advantages}

The PISCES trial highlights the importance of the patient perspective. Particular points of interest include:

- Health-related quality of life being a significant factor in patient preference for pazopanib over sunitinib

- Patient-reported outcomes may reveal differences in tolerability that are not evident from standard adverse event reporting

- Patient preference may be an important consideration in aiding choice between multiple treatment options

- The patient perspective should be considered in future research

- The internal control nature of this trial allows assessment of the abstract concept of health-related quality of life.

\section{Areas for improvement}

Due to the relatively rare nature of this type of trial design, a number of interesting points were raised in this regard and interpretation of the results for clinical practice, as follows.

- The PISCES trial is a relatively small study with only 169 patients enrolled. Further collaborative studies could be considered to confirm its findings.

- When using the same patient to test two drugs, there was a suspicion that the patient would prefer the first drug because toxicities might build up during the course of the second treatment regardless of the sequencing and despite the 2-week "washout" period.

- The decision to take efficacy out of the equation was questioned, because those patients who did progress on treatment were not allowed to answer the questionnaires. This raises the question of "should efficacy be taken out?". Many patients reflect differently if they know the treatment is working in that they are more likely to downplay side effects. Knowing a treatment is effective aids risk-benefit assessments and plays an important role in both doctor and patient preference.

- The trial design does not allow an indication of the magnitude by which patients preferred pazopanib.

- It was thought that the timing of the questionnaires, namely every 2 weeks, may have biased results. Patients were on sunitinib for 4 weeks on and 2 weeks off. Most patients on sunitinib report a peak in side effects at the end of week 4 and then an improvement of symptoms during the 2-week break. In this trial, patients on sunitinib were therefore being asked to complete their toxicity scores at the peak and trough of their symptoms, and this may not be a valid overall view or accurate comparison.

- The trial design meant that patients who "dropped out" during the first round before they reached the second round of treatment, for whatever reason, were discounted from the final analysis. This could have affected the results.

- Within the trial, dose interruptions were not allowed, which does not reflect what is done in practice. This could have biased the results, but is unlikely to have affected the magnitude of the results. In clinical practice, multiple alternative dosing schedules are used for sunitinib which may allow maintenance of quality of life, but were not implemented in the trial setting. Outside of trials, the sunitinib dose is often reduced from $50 \mathrm{mg}$ to $37.5 \mathrm{mg}$. There is some suggestion that instead of using 
the $4 / 2$ schedule, (4 weeks on, 2 weeks off) changing to a $2 / 1$ schedule may reduce grade 3 toxicity, but all the data for this are retrospective. ${ }^{24}$

\section{Local perspective}

From a local perspective, there were many positive aspects to the PISCES trial. The patients were all very enthusiastic, and overall there was a positive approach to the trial, with many patients just happy that they had treatment options. Many of our patients were excited to be "involved" with a "new drug" in a trial that was not just looking at efficacy, but also asking the opinion of patients. We also noticed that patients were happy to travel for well over an hour for the multiple visits that the trial required. At the start of the trial, pazopanib was not easily accessible by this group of patients, and there was a positive feeling about having access to a new drug. As an oncologist, it was an eye-opening phenomenon to have to declare a "physician preference" excluding efficacy considerations for essentially two well tolerated treatment regimens.

\section{Effect of PISCES on practice}

The COMPARZ trial has told us that the outcomes of sunitinib and pazopanib are similar, with good efficacy and a reasonable toxicity profile. The PISCES trial has confirmed that it is safe to choose either treatment. Ultimately, when discussing treatment options, the whole picture has to be viewed, taking into account comorbidities, patient goals, differing side effect profiles, and any evidence regarding sequencing of treatment.

\section{Involving the patient in decision-making}

With all the emphasis on patient preference, it is important to remember that not all patients want to have an active role in medical decisions. The literature reports wide variation in the extent to which patients prefer to take an active role. For example, Degner and Sloan surveyed members of the public and asked if they would like to select their own treatment if they developed cancer. Sixty-four percent said "yes" whereas $59 \%$ of actual patients wanted their physician to make treatment decisions on their behalf. ${ }^{25}$ In this survey, $75.2 \%$ of 528 patients in the UK with renal cancer reported having had a positive experience of involvement in decisionmaking regarding their treatment.

There is disagreement on whether patients should be appropriately encouraged to participate in health care decision-making and the degree of autonomy that is best. ${ }^{26}$ One strategy would be to increase patient participation by education, which may improve treatment adherence. ${ }^{27}$ Conversely, such attempts could lead to increased anxiety, as reported by Moumjid et al in 2007 when looking at shared decision-making in the setting of breast cancer. ${ }^{28}$ The 2010 English National Cancer Patient Experience Survey analyzed the responses of more than 40,000 cancer patients. Over $70 \%$ of subjects said they felt adequately involved in decisions about their treatment, but there appeared to be a generation gap, with those under the age of 55 years wanting more of a say in decisions. ${ }^{29}$ The challenge appears to lie in allowing patients to participate to the level that they desire. Understanding the effect of personality on health care decision-making style may be the key, with more studies seeking to understand the impact of personality traits on patient decision-making styles.

\section{Impact for future trials}

Due to the rapid increase in the number of targeted agents with similar efficacy in palliative oncology, it is important to consider patient preference rather than relying on reported toxicities. As demonstrated in the PISCES trial, despite the reported toxicities being similar, patient choice can be difficult to predict in the absence of evidence from patient preference studies.

Although the concept of using the same subject to test two drugs seems appealing, a significant amount of thought needs to be given as to how to analyze the results. There also needs to be an adequate washout period without concern about loss of efficacy.

In particular, future trials should address how to put a value on the degree of preference for each patient. Appropriate analysis has to incorporate the number of patients who do not manage to receive both drugs, and the "intention to treat" population should possibly be the patients who embark on the study, not just those who manage to receive some amount of both drugs. Blinding is the key to these types of studies, but consideration should also be given to creating trial designs that allows patient to choose between different routes as well as frequencies of administration.

Patient preference research in the oncology setting is essentially in its infancy, with significant scope for development in a relatively short time frame. There are now ever-increasing numbers of targeted agents for multiple malignancies, making the process of physician choice exponentially difficult. Robust results from new-generation patient preference studies will undoubtedly help this process. 
Research should not just stop at patient preference, and there is a need to continue to move the field forward and explore next-generation therapies. Cabozantinib is currently being studied against everolimus in Phase III trials, and has been shown to inhibit the VEGF receptor, KIT, and MET. ${ }^{30}$ Given that both of these agents inhibit VEGF, it may be difficult to ascertain if benefit comes from continued VEGF inhibition or from other pathways being blocked. Nivolumab has a different mechanism of action by blocking the check point inhibitor PD-1 to break or slow down the immune response, including an antitumor immune response, which could be the next wave in the treatment of metastatic RCC and paradigm shifting. ${ }^{31}$

\section{Summary}

In a situation where two drugs have demonstrated equivalent efficacy and both are available for the same indication, choosing the "right" drug for an individual patient is a very difficult task for the physician.

PISCES was a unique trial design that has aided oncology management choice of renal cancer. The focus was on patient preference rather than efficacy, personal experience or reported toxicities. It was interesting to note that despite the reported toxicities and efficacy being comparable, there was a strong patient and physician preference for pazopanib. The factors involved in this preference are multifactorial. As always, the whole picture has to be viewed, taking into account comorbidities, patient goals, and differing side effect profiles. The experience of staff in dealing with side effects also has to be considered. It is important to be able to "give one drug well" and support systems should enable the patient to be a "partner" in their care using a drug that they need to be able to tolerate over the long term.

Looking towards the future, there is a great need to increase the robustness and ways of analyzing results, and gaining acceptability of patient preference trial designs by the wider oncology community rather than just the conventional trials. Collaboration between pharmaceutical companies is vital to enable further direct comparative and patient preference trials to allow optimal choice of treatment.

As metastatic malignancies are being managed increasingly as chronic conditions, patient preference concerning drugs with comparable efficacy is going to play an increasing role in choice of agent as well as sequencing. The challenge for the physician is in allowing the patient to be involved in the decision-making process at a level that they desire.

\section{Disclosure}

The authors report no conflicts of interest in this work.

\section{References}

1. Office for National Statistics. Available from: www.ons.gov.uk. Accessed September 30, 2013.

2. Janzen NK, Kim HL, Figlin RA, Belldegrun AS. Surveillance after radical or partial nephrectomy for localized renal cell carcinoma and management of recurrent disease. Urol Clin North Am. 2003;30(4): $843-852$.

3. Motzer RJ, Bander NH, Nanus DM. Renal-cell carcinoma. $N$ Engl $J$ Med. 1996;335(12):865-875.

4. Fyfe G, Fisher RI, Rosenberg SA, Sznol M, Parkinson DR, Louie AC. Results of treatment of 255 patients with metastatic renal cell carcinoma who received high-dose recombinant interleukin-2 therapy. J Clin Oncol. 1995;13(3):688-696.

5. Yagoda A, Petrylak D, Thompson S. Cytotoxic chemotherapy for advanced renal cell carcinoma. Urol Clin North Am. 1993;20(2): 303-321.

6. Farmer B. Magic bullet for cancer. Daily Mail Online. 2006. Available at: http://www.dailymail.co.uk/health/article-398444/Magic-bulletcancer.html. Accessed September 30, 2013.

7. Na X, Wu G, Ryan CK, Schoen SR, Di'santagnese PA, Messing EM. Overproduction of vascular endothelial growth factor related to von Hippel-Lindau tumor suppressor gene mutations and hypoxiainducible factor-1 alpha expression in renal cell carcinomas. $J$ Urol. 2003;170(2 Pt 1):588-592.

8. Mendel DB, Laird AD, Xin X, et al. In vivo antitumor activity of SU11248, a novel tyrosine kinase inhibitor targeting vascular endothelial growth factor and platelet-derived growth factor receptors: determination of a pharmacokinetic/pharmacodynamic relationship. Clin Cancer Res. 2003;9(1):327-337.

9. Motzer RJ, Hutson TE, Tomczak P, et al. Sunitinib versus interferon alfa in metastatic renal-cell carcinoma. $N$ Engl $J$ Med. 2007;356(2):115-124.

10. Hudes G, Carducci M, Tomczak P, et al. Temsirolimus, interferon alfa, or both for advanced renal-cell carcinoma. N Engl J Med. 2007;356(22): 2271-2281.

11. Escudier B, Pluzanska A, Koralewski P, et al. Bevacizumab plus interferon alfa-2a for treatment of metastatic renal cell carcinoma: a randomised, double-blind phase III trial. Lancet. 2007;370(9605): 2103-2111.

12. Motzer RJ, Escudier B, Oudard S, et al. Efficacy of everolimus in advanced renal cell carcinoma: a double-blind, randomised, placebocontrolled phase III trial. Lancet. 2008;372(9637):449-456.

13. Hu-lowe DD, Zou HY, Grazzini ML, et al. Nonclinical antiangiogenesis and antitumor activities of axitinib (AG-013736), an oral, potent, and selective inhibitor of vascular endothelial growth factor receptor tyrosine kinases 1, 2, 3. Clin Cancer Res. 2008;14(22): 7272-7283.

14. Rini BI, Escudier B, Tomczak P, et al. Comparative effectiveness of axitinib versus sorafenib in advanced renal cell carcinoma (AXIS): a randomised phase 3 trial. Lancet. 2011;378(9807): 1931-1939.

15. Rini BI, Grünwald V, Fishman MN, et al. Axitinib for first-line metastatic renal cell carcinoma (mRCC): overall efficacy and pharmacokinetic analyses from a randomized phase II study. J Clin Oncol. 2012;30(Suppl 18):Abstr 4503.

16. Motzer RJ, Hutson TE, Cella D, et al. Pazopanib versus sunitinib in metastatic renal-cell carcinoma. N Engl J Med. 2013;369(8): 722-731.

17. Gore ME, Larkin JM. Challenges and opportunities for converting renal cell carcinoma into a chronic disease with targeted therapies. $\mathrm{Br}$ J Cancer. 2011;104(3):399-406. 
18. Harshman LC, Xie W, Bjarnason GA, et al. Conditional survival of patients with metastatic renal-cell carcinoma treated with VEGFtargeted therapy: a population-based study. Lancet Oncol. 2012;13: 927-935.

19. Thomas R, Godward S, Makris A, Bloomfield D, Moody AM, Williams M. Giving patients a choice improves quality of life: a multi-centre, investigator-blind, randomised, crossover study comparing letrozole with anastrozole. Clin Oncol ( $R$ Coll Radiol). 2004;16(7):485-491.

20. National Institute for Clinical Excellence. NICE recommends a new treatment for kidney cancer. Available from: http://www.nice. org/newsroom/pressreleases/pazopanibForRenalCellCarcinoma.jsp. Accessed September 30, 2013

21. Sternberg CN, Davis ID, Mardiak J, et al. Pazopanib in locally advanced or metastatic renal cell carcinoma: results of a randomized phase III trial. J Clin Oncol. 2010;28(6):1061-1068.

22. Escudier BJ, Porta C, Bono P. Patient preference between pazopanib and sunitinib: results of a randomized double-blind, placebo-controlled, crossover study in patients with metastatic renal cell carcinoma-PISCES study, NCT 01064310. J Clin Oncol. 2012;30(Suppl 18):Abstr CRA4502.

23. Kumar R, Crouthamel MC, Rominger DH, et al. Myelosuppression and kinase selectivity of multikinase angiogenesis inhibitors. Br J Cancer. 2009;101(10):1717-1723.

24. Najjar YG, Elson P, Wood LS, Garcia JA, Dreicer R, Rini BI. Association of a 2-weeks-on and 1-week-off schedule of sunitinib with decreased toxicity in metastatic renal cell carcinoma. J Clin Oncol. 2013;31(Suppl 6):Abstr 406

25. Degner LF, Sloan JA. Decision making during serious illness: what role do patients really want to play? J Clin Epidemiol. 1992;45(9):941-950.
26. Flynn KE, Smith MA. Personality and health care decision-making style. J Gerontol B Psychol Sci Soc Sci. 2007;62(5):P261-P267.

27. Wilson SR, Strub P, Buist AS, et al. Shared treatment decision making improves adherence and outcomes in poorly controlled asthma. Am J Respir Crit Care Med. 2010;181(6):566-577.

28. Moumjid N, Carrère MO, Charavel M, Brémond A. Clinical issues in shared decision-making applied to breast cancer. Health Expect. 2003;6(3):222-227.

29. El Turabi A, Abel GA, Roland M, Lyratzopoulos G. Variation in reported experience of involvement in cancer treatment decision making: evidence from the National Cancer Patient Experience Survey. Br J Cancer. 2013;109(3):780-787.

30. Vaishampayan U. Cabozantinib as a novel therapy for renal cell carcinoma. Curr Oncol Rep. 2013;15(2):76-82.

31. Bailey A, Mcdermott DF. Immune checkpoint inhibitors as novel targets for renal cell carcinoma therapeutics. Cancer J. 2013;19(4): $348-352$.

32. Minasian LM, Motzer RJ, Gluck L, Mazumdar M, Vlamis V, Krown SE. Interferon alfa-2a in advanced renal cell carcinoma: treatment results and survival in 159 patients with long-term follow-up. J Clin Oncol. 1993;11(7):1368-1375.

33. Escudier B, Eisen T, Stadler WM, et al. Sorafenib in advanced clear-cell renal-cell carcinoma. $N$ Engl J Med. 2007;356(2):125-134.

34. Motzer RJ, Escudier B, Tomczak P, et al. Axitinib versus sorafenib as second-line treatment for advanced renal cell carcinoma: overall survival analysis and updated results from a randomized phase 3 trial. Lancet Oncol. 2013;14(6):552-562.
Patient Preference and Adherence

\section{Publish your work in this journal}

Patient Preference and Adherence is an international, peer-reviewed, open access journal focusing on the growing importance of patient preference and adherence throughout the therapeutic continuum. Patient satisfaction, acceptability, quality of life, compliance, persistence and their role in developing new therapeutic modalities and compounds to

\section{Dovepress}

optimize clinical outcomes for existing disease states are major areas of interest. This journal has been accepted for indexing on PubMed Central. The manuscript management system is completely online and includes a very quick and fair peer-review system. Visit http://www.dovepress.com/ testimonials.php to read real quotes from published authors. 